\title{
High Frequency Manipulation at Futures Expiry: The Case of Cash Settled Indian Single Stock Futures
}

\author{
Sobhesh K. Agarwalla (sobhesh@iimahd.ernet.in) \\ Joshy Jacob (joshyjacob@iimahd.ernet.in) \\ Jayanth R. Varma (jrvarma@iimahd.ernet.in)
}

W.P. No. 2014-02-01

February 2014

The main objective of the Working Paper series of IIMA is to help faculty members, research staff, and doctoral students to speedily share their research findings with professional colleagues and to test out their research findings at the pre-publication stage.

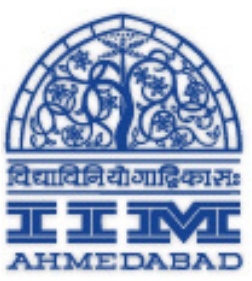

\section{INDIAN INSTITUTE OF MANAGEMENT AHMEDABAD - 380015 \\ INDIA}




\title{
High Frequency Manipulation at Futures Expiry: The Case of Cash Settled Indian Single Stock Futures
}

\author{
Sobhesh K. Agarwalla (sobhesh@iimahd.ernet.in)* \\ Joshy Jacob (joshyjacob@iimahd.ernet.in)* \\ Jayanth R. Varma (jrvarma@iimahd.ernet.in)*
}

\begin{abstract}
Futures markets are known to be vulnerable to manipulation, and despite the presence of a variety of mechanisms to prevent such manipulation, instances of market manipulation have been found in some of the largest and most liquid futures markets worldwide. In 2013, the Securities and Exchange Board of India identified a case of alleged manipulation (in September 2012) of the settlement price of cash settled single stock futures based on high frequency circular trading. As is well known, it is easy for any well-endowed manipulator to manipulate the price; the real challenge for the manipulator is to make the manipulation profitable. The use of high frequency circular trading of the form alleged in the SEBI order makes many forms of manipulation profitable, and makes futures market manipulation a much bigger problem than previously thought.

As argued by Pirrong (2004), it is more practical to detect and punish manipulation than to try and prevent it. We develop an econometric technique that uses high frequency data and which can be integrated with the automated surveillance system to identify suspected cases of high frequency manipulation at futures expiry. We then use these techniques to identify a few suspected cases of manipulation. Needless to say, human judgement needs to be applied to decide which, if any, of these cases need to be taken up for investigation (and, after that, possible prosecution). This judgement is beyond the scope of our paper, and we refrain from making any judgement on whether any of the identified cases constitutes actual market manipulation.
\end{abstract}

*All the authors are faculty members of the Indian Institute of Management, Ahmedabad. 


\section{Introduction}

Futures markets are known to be vulnerable to manipulation, and despite the presence of a variety of mechanisms to prevent such manipulation, instances of market manipulation have been found in some of the largest and most liquid futures markets worldwide. In 2013, the Securities and Exchange Board of India identified a disturbing case of alleged manipulation using high frequency trading in the Indian stock futures market. This alleged manipulation exploited several interesting characteristics of the Indian single stock futures market: (a) the futures contract is cash settled, (b) the settlement price is not based on a call auction or special session, but is the volume weighted average price (VWAP) during the last half an hour of trading in the cash market on the expiry date, and (c) anecdotal evidence ${ }^{1}$ suggests that the Indian market is more vulnerable to circular trading in which different entities associated with the same person trade with each other to create a false market. As is well known, it is easy for any well-endowed manipulator to manipulate the price; the real challenge for the manipulator is to make the manipulation profitable. The use of high frequency circular trading of the form alleged in the SEBI order makes many forms of manipulation profitable, and makes futures market manipulation a much bigger problem than previously thought.

This form of market manipulation corroborates the argument in Pirrong (2004) that it is more practical to detect and punish manipulation than to try and prevent it. We discuss econometric tools and techniques for detecting high frequency manipulation at futures expiry using automated surveillance techniques. We then use these techniques to identify a few suspected cases of manipulation. Needless to say, human judgement needs to be applied to decide which, if any, of these cases need to be taken up for investigation (and, after that, possible prosecution). This judgement is beyond the scope of our paper, and we refrain from making any judgement on whether any of the identified cases constitutes actual market manipulation.

\section{Literature Review}

\subsection{Futures Market Manipulation}

Practitioners, academics and regulators have long recognized that futures markets are vulnerable to manipulation. A variety of mechanisms like position limits have been implemented to prevent such

\footnotetext{
${ }^{1}$ There are numerous instances of circular trading in the Indian market. For instance, in September 2013, SEBI bars 34 entitites from capital market due to synchronized trading by connected persons. (link: http://www.sebi. gov.in/cms/sebi_data/pdffiles/26411_t.pdf
} 
manipulation. Nevertheless, market manipulation does take place in some of the largest and most liquid futures markets. To give just a few examples:

- Jeanneau and Scott $(2001,2002)$ describe the squeezes that took place in the German government bond futures markets in 2001 and 2002. These are large markets which are extremely important for price discovery in the entire eurozone interest rate market.

- Järvinen and Käppi (2004) provide evidence of occasional squeezes in the German government bond futures markets in 1998 and 1999.

- In 2011, the South Korean securities regulator imposed penalties on the Korean affiliate of a large European bank for manipulating the Korean index futures market in November 2010 (Financial Services Commission Korea, 2011). The manipulation caused the Korea Stock market index to drop by $2.79 \%$ in the last ten minutes of trading and allowed the manipulator to make a profit of $\$ 40$ million.

- Since 2009, regulators in a number of different jurisdictions including the United Kingdom, United States, Canada, Japan, Switzerland and the European Union have been investigating a number of large banks for attempted manipulation of the London Inter Bank Offer Rate (LIBOR) which is an important interest rate benchmark for several trillion dollars of interest rate derivatives (Wheatley, 2012).

Pirrong (2010) distinguishes between manipulation based on market power and manipulation based on fraudulent devices like spreading of rumours, use of wash trades and misreporting of prices. The LIBOR manipulation mentioned above falls in the category of fraud (misreporting of prices). All the other cases above are examples of market power manipulation - they all involve a trader taking positions large enough to move the price. In physically settled futures contracts, a common form of market power manipulation involves accumulating a large futures position that allows the manipulator to demand delivery of more of the commodity than is available in the delivery market at the competitive price. Position limits are designed to prevent this by prohibiting anybody from accumulating such a large position.

Kumar and Seppi (1992) develop a model of market power manipulation in a cash settled futures contract. They describe the intuition behind their model as follows:

For example, after establishing a 'long' futures position, the settlement price can be artificially bid up by buying in the spot market. This is called 'punching the settlement 
price.' If the futures position is larger than the spot position, the net expected gain (i.e., profit on futures less loss on the spot) is positive. 'Cash settlement' allows the manipulator to convert 'paper' capital gains into cash directly without taking delivery of the misvalued underlying asset. In effect, 'cash settlement' acts as an infinitely liquid market in which pre-existing futures positions are closed out. It is the resulting pattern of implicit liquidity at delivery preceded by a comparatively less liquid spot market (in which trading affects the price) which makes manipulation feasible.

\subsection{Detection versus Prevention of Manipulation}

There has been a lively debate in the literature on whether the best response to futures market manipulation is to detect (and punish) manipulation or to prevent manipulation. On the one hand, Markham (1991) argues that manipulation is so hard to detect and prove that it is an unprosecutable crime which must be prevented before it occurs. On the other hand, Pirrong (2004) argues that it is more efficient to deter manipulation by detecting and punishing the offender.

The category of fraudulent market power manipulation that we have identified is not amenable to prevention through measures like position limits. By accumulating the futures positions through multiple entities, even the most stringent position limits can be easily circumvented. Detection followed by deterrent punishment is the only feasible way to deal with the problem.

The only preventive measure which could be even partly effective is a more robust way of calculating the settlement price. The use of the volume weighted average of the last thirty minutes instead of the last traded price is itself a step in this direction to make manipulation harder. In an illiquid stock, this might be inadequate to stop a manipulator using circular trading on a large scale.

Hillion and Suominen (2004) discuss several alternative mechanisms that have been used in different exchanges for determining the closing price:

- The closing price is an average of a random sample of prices near the close.

- The closing price is the mid price of the best bid and ask of the market makers.

- The closing price equals the price of the last trade, but the exchange closes trading, on any given stock, at a random point in time.

- The closing price is determined by a call auction. 
Other more robust measures that could be tried include:

- Use of trimmed means, medians or other methods that limit the influence of a single observation in the average.

- Use of the simple (unweighted) average of the price at the end of each minute during the last half hour.

All these attempts to make the closing price more robust have their own disadvantages. Moreover, methods designed to deter simple forms of manipulation may be vulnerable to more sophisticated variants of the same strategy. There is therefore merit in adopting the viewpoint of Pirrong (2004) that it is more efficient to deter manipulation by detecting and punishing the offender.

\section{Stylized Model for High Frequency Market Manipulation}

\subsection{The September 27, 2012 Episode in India}

Our stylized models were inspired by an episode in India which we now describe. In India, single stock futures were cash settled based on the closing price in the cash market on the expiry day. Closing prices in the cash market were computed as volume weighted average traded prices during the last half hour of trading. This was in contrast to many other global equity derivative markets where the cash settlement was usually based on the price determined through a call auction. For example, the US stock index futures were cash settled using the opening price on expiry day, and the opening price is discovered in a pre-opening session.

In 2013, the Indian securities regulator, Securities and Exchange Board of India, took action against a group of entities involved in the alleged manipulation of the settlement price of a single stock futures contract (Securities and Exchange Board of India, 2013a). The interim prohibitions imposed by this order were lifted in a subsequent order (Securities and Exchange Board of India, 2013b), and investigations are ongoing. The salient features of this episode were as follows:

- On September 27, 2012 (the expiry day of the September futures contract), the stock price in the cash market moved from ₹69 to ₹88 between 15:20:09 and 15:29:46, i.e. a $26 \%$ upward movement during the last 10 minutes of the trading day.

- The price swing on that day was so extraordinary that the day's low and high were the low and high for the stock for the whole month. Most of this swing happened in the last few minutes. 
- The official closing price (volume weighted average price during the last 30 minutes) was about 9.9\% higher than the volume weighted average price during the rest of the day. This could be taken as a rough measure of how this extraordinary trading impacted the settlement price of the futures contract.

- The price movement and trading volume in the scrip was concentrated during the last 3 minutes of trading on that day. The volume transacted in one minute on September 27, 2012 exceeded the total daily volume in any other day in the month.

- There was no new information that could justify such a large price movement.

- Practically, the entire price movement was reversed on the next day.

- The open interest in the futures on expiry day was quite high compared to the previous month.

In its initial order (Securities and Exchange Board of India, 2013a), the regulator found evidence that most of the trading volume was between different entities associated with the same manipulator. Collectively these entities held an open interest of 7.2 million shares (₹566 million) in the September futures representing $76 \%$ of the entire open interest in the contract.

\subsection{High Frequency Manipulation of the Settlement Price}

The September 27, 2012 episode represents a very important twist to the Kumar and Seppi (1992) model of manipulating cash settled futures. A simple calculation based on the open interest and the trading volume would show that the gain from the futures was not sufficient to make the manipulation profitable. The cash market trading volume in the last three minutes exceeded the alleged manipulators' open interest in the futures. Moreover the volume weighted average price in those three minutes was ₹14.5 more than the undisturbed price (volume weighted average price prior to 3 $\mathrm{pm}$ ), but the futures settlement price (volume weighted average price of last 30 minutes in the cash market) was only ₹7 more than the undisturbed price. So the losses in the cash market would have been about twice the gain in the futures market.

The key to the profitability of the alleged manipulation is that it involved large trading between different entities allegedly associated with the same manipulator. The alleged manipulator was buying with one hand and selling with the other. At the end of the day, the net long position accumulated by the alleged manipulator in the cash market was quite small. There was a much 
larger profit in the futures market where the alleged manipulator held more than three-fourth of the open interest.

The alleged manipulation found in the September 27, 2012 episode straddles the classification scheme of Pirrong (2010) - it is a fraudulent market power manipulation. There is clearly an exercise of market power involved in moving the settlement price by nearly $10 \%$ as well as in accumulating $76 \%$ of the open interest in the futures market. But this market power is coupled with two elements of alleged fraud:

- The alleged circular trading within the same group of connected entities moves the settlement price without any economic interest changing hands.

- The splitting of the open interest in the futures market between several entities circumvents any position limits that might have been imposed.

High frequency trading is critical in the success of this form of fraudulent market power manipulation. If the trading were done slowly, people holding short futures positions and people with a bearish view of the stock would step in to foil the manipulation attempt by selling large amounts of stock to the manipulator. If the manipulator is forced to buy from others instead of buying from its own connected entities, it would suffer losses while moving the settlement price. The economics of the manipulation game would change drastically and the manipulation would in all probability become unviable.

The manipulator succeeds only by trading so fast that the bears do not have time to understand what is going on and undertake any counter measures. Thus successful manipulation of the September 27, 2012 genre requires three critical elements:

1. High frequency trading to blindside the victims of the manipulation.

2. Market power in the form of large futures positions and large trading volumes.

3. Fraud in the form of circular trading with related entities.

\subsection{High Frequency Manipulation of Execution Algorithms}

Even if circular high frequency manipulation does not move the settlement price too much, it may still become profitable by exploiting price insensitive execution algorithms at futures expiry. By price insensitive execution algorithms, we mean algorithms that place market orders in the market 
without taking into account prevailing market prices. If prices are dislocated, price conscious traders (whether human or algorithmic) will change their trading strategies - they would avoid buying at artificially inflated prices and selling at artificially depressed prices. But by definition, price insensitive execution algorithms will continue to trade with equal readiness at dislocated prices. It is by exploiting these algorithms that the manipulator could hope to make money. This is clearly related to the argument of Arnoldi (2012) that human traders attempt to 'mislead' algos or make algorithms 'make mistakes', and as a result, the algorithmic models end up being manipulated by humans instead of the other way around.

Arbitrageurs often use price insensitive execution algorithms as part of their arbitrage strategy. In a cash settled market, an arbitrageur who has shorted futures and bought in the cash market needs to replicate the settlement price in the cash market to unwind this position. Since the arbitrageur has offsetting positions in cash and futures, the average price at which he sells in the cash market is immaterial as long as that average price equals the settlement price in the futures market. He makes no attempt to defend himself against a market manipulator because no defence is needed. On the other hand, a manipulator with a pre-existing position in the cash market would therefore try to dislocate the price (possibly for a very short period) and then attempt to offload his pre-existing position to a price insensitive algorithm at the dislocated price.

Since the settlement price is not determined by a call auction, arbitrageurs and others who seek to replicate the settlement price in the cash market must resort to a variety of execution algorithms. A simple algorithm is to slice the order into say 60 equal size market orders executed every 30 seconds during the final half hour of trading on expiry day. A more sophisticated algorithm might target a constant participation rate to better reflect the fact that the settlement price is a volume weighted average and not a simple average. Neither algorithm would or should take the market price into account in deciding its execution. To achieve their purpose, these execution algorithms must be price insensitive - they must buy or sell regardless of the market price.

For this reason, we believe that even a transient price spike at expiry that (a) is accompanied by unusual volume and (b) is quickly reversed (implying that the price change was not due to any new information about fundamentals) should be regarded as a potential case of high frequency market manipulation. Regulators should take this up for further analysis in the second and third stages of the three stage process for manipulation detection that we describe later in this paper. 


\section{Methodology}

\subsection{Identifying Suspected High Frequency Manipulation}

Detection of market manipulation can be broken down into three steps:

1. Suspected cases of high frequency manipulation need to be identified using automated surveillance techniques.

2. Human judgement then needs to be applied to identify cases which prima facie appear to be consistent with a market manipulation episode.

3. These suspected cases need to be taken up for investigation and possible prosecution.

In this paper, we carry out a statistical analysis designed to demonstrate the feasibility of the first step. We also attempt part of the second step. No claim is made that the instances emerging out of this exercise does or does not constitute actual market manipulation as that conclusion can be arrived at only if a statutory authority undertakes the all important third step.

We identify suspected high frequency manipulation by looking for the following conditions:

- This must be associated with abnormal trading volumes in the last thirty minutes.

- There must be a dislocation of the last traded price on the expiry day.

Any episode satisfying the above conditions could potentially allow a high frequency manipulator to exploit price insensitive algorithms during the expiry period.

To constitute a profitable manipulation of the settlement price, two additional conditions must be met:

- There must be a dislocation of the settlement price (30 minute volume weighted average price).

- There must be a large open interest in the expiring contract relative to the open interest on the expiry dates in the previous month and in the next month.

\subsection{Indicators of Abnormal Trading Volume}

We are interested in high frequency manipulation and so we need to look for unusual high trading volumes during specific minutes near the close. Moreover, we are looking for manipulation during 
the closing minutes on expiry day when volumes are expected to be high even in the absence of manipulation. This means that we need a model of minute by minute volumes on expiry day. The standard model for taking into account the intra-day seasonality is the Flexible Fourier Form (FFF) regression model which was first introduced by Gallant (1981) and was later used by Andersen and Bollerslev (1997a,b, 1998a,b). In addition to using a flexible Fourier form to model the minute by minute seasonality of trading volume, we also need to control for (a) changes in the open interest in the futures contracts and (b) the aggregate trading volume on the day prior to the last half-hour (the settlement period). The regression model is:

$$
\begin{aligned}
\ln \left(Q_{m, n, t}\right)=P_{0} & +\sum_{k=1}^{12}\left[\lambda_{k} \sin \left(\frac{2 \pi k n}{N}\right)+\delta_{k} \cos \left(\frac{2 \pi k n}{N}\right)\right] \\
& +P_{1} \overline{\ln \left(Q_{N S P, m, t}\right)}+P_{2} \ln \left(1+R O V_{m, t}\right) \\
& +P_{3} \ln \left(1+U W D_{m, t}\right)+P_{4} \ln \left(1+N E W P_{m, t}\right)+\epsilon_{m, n, t}
\end{aligned}
$$

where

$Q_{m, n, t}$ is the actual trading volume of stock $m$ in minute $n$ of the last half hour of trading on expiry day $t$

$\lambda_{k}$ and $\delta_{k}$ are the Fourier coefficients that model the minute of day seasonality of trading during the last half hour of trading on all expiry days.

$\overline{\ln \left(Q_{N S P, m, t}\right)}$ is the average of the log of volume per minute of stock $m$ on expiry day $t$ before the last half hour (non settlement period)

$R O V_{m, t}$ (rollover), $U W D_{m, t}$ (unwinding) and $N E W P_{m, t}$ (new positions) are variables computed from $\Delta_{N E A R, m, t}$ (the decrease in open interest of stock $m$ on the expiring contract on expiry day $t$ ) and $\Delta_{N E X T, m, t}$ (the increase in open interest of stock $m$ on the next month contract on expiry day $t$ ). The lower of $\Delta_{N E A R, m, t}$ and $\Delta_{N E X T, m, t}$ is regarded as the stock $m$ 's quantity rolled over $\left(R O V_{m, t}\right)$ into the next month on expiry day $t$ and the balance of $\Delta_{N E A R, m, t}$ is assumed to be the unwinding $\left(U W D_{m, t}\right)$ on expiry day $t$. If this computation leads to a negative rollover and if $\Delta_{N E A R, m, t}$ is negative, then the rollover is set to zero, else the negative of the computed quantity is regarded as the new positions of stock $m\left(N E W P_{m, t}\right)$ created on expiry day $t$.

$\epsilon_{m, n, t}$ is the regression residual which is used to measure the unusual trading volume of stock $m$ in minute $n$ of the last half hour of trading on expiry day $t$. Specifically, the trading volume in minute $n$ on day $t$ is unusually high if $\epsilon_{m, n, t}>3 \sigma$ where $\sigma$ is the standard deviation of $\epsilon_{m, n, t}$. 
We supplement this measure with a simple model free measure of abnormal volume:

- We compute the inter quartile range (IQR) as a robust measure of dispersion of minute by minute trading volumes in the last half hour of trading on the expiry day.

- The volume in a specific minute is abnormally high only if it is at least 1.5 IQRs above the third quartile of trading volumes in the last half hour. (Under the assumption of a normal distribution, this cutoff would correspond to 2.7 standard deviations above the mean implying a right tail probability of $0.35 \%$.)

- In addition, to be regarded as abnormally high, the volume in a specific minute must be at least 1.5 IQRs above the highest trading volume in any minute prior to the last half hour of trading.

\subsection{Indicators of Dislocation of End-of-Day (EOD) Prices}

Cumming and Johan (2008, Table 1) provide a comprehensive list of indicators of market manipulation that are tracked by automated surveillance software. Only a few of these are relevant to the case of closing price manipulation that are of concern to us. Cumming et al. (2012) discuss manipulation of End-of-Day (EOD) prices in great detail and enumerate tests used by standard surveillance software to detect this. Broadly, these tests adopt the following procedure:

- Compute the difference between the closing price and the price prevailing shortly before the close.

- Compare this price change with the standard deviation of similar price changes in the recent past to identify unusually large price changes.

- Compute the price reversal - the percentage of the price change during the close that is reversed at the next day opening price. A large price reversal suggests that the price movement at the close was not caused by any new information that came in during the closing minutes.

- An unusually large price change at the close that is substantially reversed on the next day is likely to be a price manipulation.

Our definition of an abnormal movement is as follows: 
- The $\mathrm{z}$-value of the absolute return in the last 30 minutes must be at least 3.0 (The absolute return in the last 30 minutes must be at least three standard deviations above the mean where both the mean and the standard deviation are estimated from the last 30 minute returns on all expiry days for that stock. The return is computed using the last traded price and not the settlement (official closing) price.

- Our second test for abnormal returns controls for market wide returns. Rather than the raw return, we work with abnormal excess returns (raw return minus the index return over the same period). The excess return in last 30 minutes must exceed $5 \%$ in absolute value. The return is computed using the last traded price and not the settlement (official closing) price.

- The reversal on next day must exceed either $5 \%$ or $50 \%$ of the excess return in last 30 minutes. The reversal is computed from the last traded price on the expiry day and not the settlement (official closing) price.

- The above reversal could happen either in 1 minute or in 30 minutes.

\subsection{Indicators of Dislocation of Settlement Price}

Any episode satisfying the above conditions of abnormal volume and abnormal price movement could potentially represent an attempt by a high frequency manipulator to exploit price insensitive algorithms during the expiry period. But these episodes may not represent an attempt to move the futures settlement price and profit from positions in the futures market.

We measure the suspected manipulator's success in dislocating the settlement price by two methods:

1. We compute the difference between the settlement price and the volume weighted average price considering the period before the last half hour of trading.

2. We compute the difference between the settlement price and the volume weighted average price during the last 30 minutes excluding the abnormal minutes (identified by the IQR (inter quartile range) criterion).

Clearly, there is no manipulation of the settlement price if both these indicators are small.

Furthermore a dislocation of the settlement price is profitable to the manipulator only if he carries a large open interest into the expiry day. We therefore expect the market wide open interest on the day prior to the eve of the expiry day to be high. We test for this by computing the ratio of market 
wide open interest on expiry-eve in the event month to the average expiry-eve open interest in the preceding and succeeding month.

\section{$5 \quad$ Data and Results}

\subsection{Data}

Single stock futures contracts were introduced in the Indian market in 2001. During the year 2011-12, the average daily trading in the Indian single stock futures market was ₹163 billion (approximately $\$ 3.41$ billion) making it one of the largest single stock futures markets in the world.

We used high frequency data from the National Stock Exchange on all single stock futures in India from November 2001 to February 2013. There were a total of 322 stocks and 136 expiry days in this sample. Since some stocks had futures trading on them only for a part of the period, there were 19,568 stock-expiry days in all.

To estimate Eq 1, we use data on minute-by-minute volume during the last 30 minutes of trading for each of these expiry dates - the total number of observations was 589,646.

The data on prices and open interest was also obtained from the National Stock Exchange.

\subsection{Minute-by-minute Seasonality of Trading Volume}

The flexible Fourier form described in Eq 1 reveals a very marked intra-day (minute by minute) seasonality of trading volume during the last half-hour on expiry day as shown in Figure 1. This plot is obtained by ignoring all the terms other than the Fourier terms in Eq. 1, taking exponents to convert from log volumes to actual volumes, and multiplying by 100 to obtain a percentage of average volumes. 
Minute by minute cash volume pattern at futures expiry

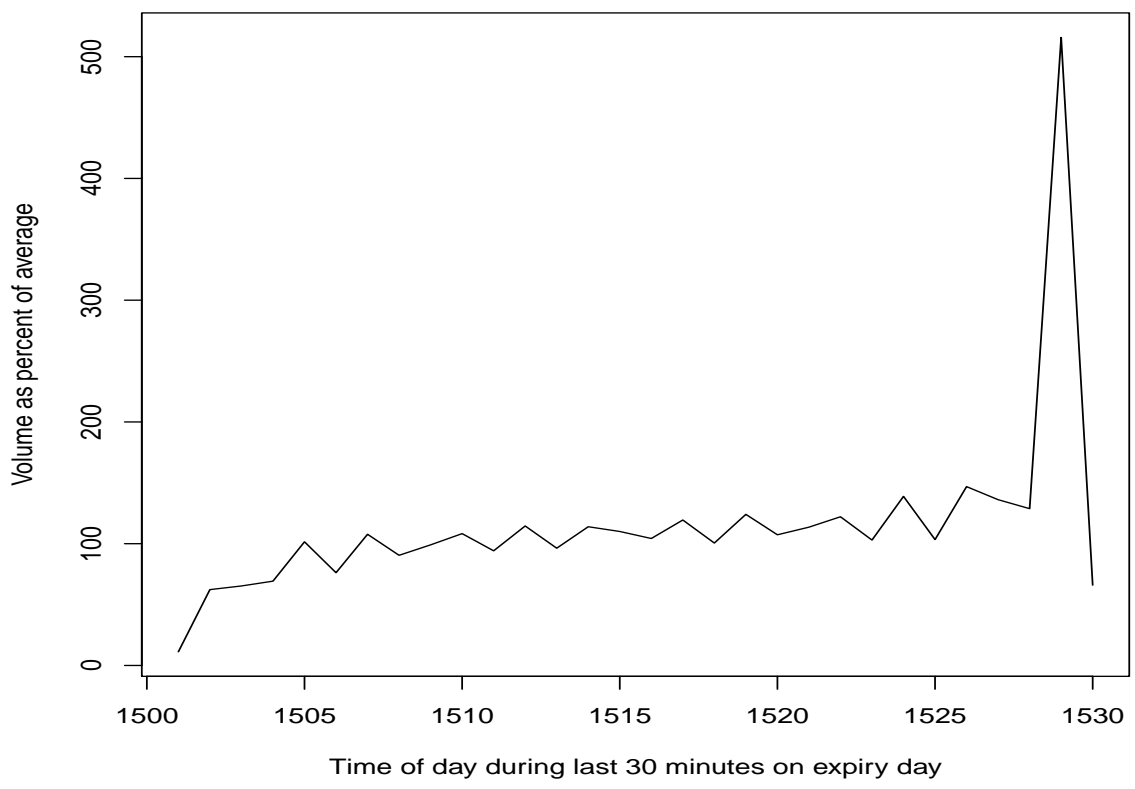

Figure 1: Minute by minute seasonality pattern of trading volume during the last half-hour on expiry day obtained from the sinusoid terms of the flexible Fourier form regression model. The figure indicates a large spike in volume near the close.

\subsection{High Frequency Manipulation of Last Traded Price}

Applying the above methodology, we identified 8 events (involving 7 companies $^{2}$ ) of possible high frequency manipulation of last traded price on futures expiry. The possible manipulation events are summarized in Table 1 and Table 2. Detailed plots of each event are available in the Appendix.

\footnotetext{
${ }^{2}$ These companies are referred to in this paper by a serial number. The NSE ticker symbols corresponding to these serial numbers are CMC, KPIT, MAHSEAMLES, PATNI, PURVA, RUCHISOYA, ULTRACEMCO
} 
Table 1: Summary of possible manipulation events: Part A

\begin{tabular}{lrrrr}
\hline & Company 1 & Company 2 & Company 3 & Company 4 \\
\hline Date & 20090129 & 20080327 & 20080327 & 20060125 \\
Max Volume: Time & 1529 & 1507 & 1522 & 1529 \\
Max Volume: Z value & 3.67 & 3.13 & 3.69 & 3.19 \\
Max Volume: IQRs above Q3 & 1.83 & 24.01 & 3.58 & 5.02 \\
> 3 sigma: Count & 3 & 1 & 6 & 1 \\
> 3 sigma: \% of Day Volume & 14.92 & 15.44 & 40.15 & 14.40 \\
> 1.5 IQR: Count & 1 & 1 & 4 & 1 \\
> 1.5 IQR: \% of Day Volume & 8.13 & 15.44 & 33.88 & 14.40 \\
Excess Ret last 30 min (\%) & 6.00 & -5.70 & 17.20 & -6.20 \\
Z value absolute returns last 30 min & 3.25 & 3.15 & 10.74 & 3.57 \\
Close v pre 3 pm VWAP (\%) & -0.84 & -3.72 & 5.48 & -1.78 \\
Close v outlier excluded close (\%) & 0.28 & 1.19 & 1.53 & -0.72 \\
Reversal 1 min (\%) & -7.40 & 3.60 & -6.50 & 5.10 \\
Reversal 30 min (\%) & -3.70 & 2.70 & -6.40 & 4.70 \\
Open Interest Ratio & 3.75 & 0.85 & 1.50 & 1.94 \\
\hline
\end{tabular}

Table 2: Summary of possible manipulation events: Part B

\begin{tabular}{lrrrr}
\hline & Company 5 & Company 6 & Company 6 & Company 7 \\
\hline Date & 20080828 & 20120426 & 20120927 & 20090429 \\
Max Volume: Time & 1529 & 1529 & 1529 & 1518 \\
Max Volume: Z value & 3.34 & 4.60 & 4.35 & 3.94 \\
Max Volume: IQRs above Q3 & 6.35 & 6.50 & 17.72 & 3.87 \\
> 3 sigma: Count & 1 & 5 & 2 & 8 \\
> 3 sigma: \% of Day Volume & 11.65 & 20.81 & 49.47 & 40.57 \\
> 1.5 IQR: Count & 2 & 1 & 4 & 1 \\
> 1.5 IQR: \% of Day Volume & 27.46 & 9.26 & 55.60 & 11.06 \\
Excess Ret last 30 min (\%) & 11.80 & 6.90 & 21.30 & 5.70 \\
Z value absolute returns last 30 min & 6.93 & 3.95 & 13.60 & 3.36 \\
Close v pre 3 pm VWAP (\%) & 8.33 & 1.33 & 9.86 & 1.16 \\
Close v outlier excluded close (\%) & 4.46 & 0.92 & 11.47 & -0.06 \\
Reversal 1 min (\%) & -5.30 & -3.90 & -12.50 & -4.70 \\
Reversal 30 min (\%) & -3.50 & -5.50 & -13.60 & -4.90 \\
Open Interest Ratio & 0.59 & 1.34 & 2.87 & 1.66 \\
\hline
\end{tabular}

\section{Variable definitions:}

Date The expiry date (YYYYMMDD format) on which the suspected manipulation took place.

Max Volume: Time The time of day (HHMM format) at which the maximum abnormal volume took place

Max Volume: $\mathbf{Z}$ value The $\mathrm{z}$-value of the maximum abnormal volume (the standardized residual from the flexible Fourier form regression)

Max Volume: IQRs above Q3 The number of IQRs (inter quartile ranges) by which the maximum abnormal volume exceeds the third quartile of trading volumes in the last half hour on the event day.

$>3$ sigma: Count Number of minutes in which the trading volume was three standard deviations above the value predicted by the flexible Fourier form regression. 
$>3$ sigma: \% of Day Volume The percentage of the event day trading volume accounted for by the abnormal minutes as defined by the above three standard deviations criterion.

> 1.5 IQR: Count Number of minutes in which the trading volume was 1.5 IQRs (inter quartile ranges) above the third quartile of trading volumes in the last half hour on the event day

> 1.5 IQR: \% of Day Volume The percentage of the event day trading volume accounted for by the abnormal minutes as defined by the above IQR criterion.

Excess Ret last 30 min (\%) The percentage return on the stock in the last 30 minutes on the event day in excess of the Nifty return over the same period. The return is computed using the last traded price and not the settlement (official closing) price.

$\mathbf{Z}$ value absolute returns last $30 \mathrm{~min}$ The $\mathrm{z}$-value of the absolute return in the last 30 minutes obtained by dividing the absolute return by the standard deviation of last 30 minute returns on all expiry days for that stock. The return is computed using the last traded price and not the settlement (official closing) price.

Close vs. pre 3 pm VWAP (\%) The percentage change between the volume weighted average price prior to $3 \mathrm{pm}$ and the settlement (official closing) price on the event day.

Close vs. outlier excluded close (\%) The percentage change between the volume weighted average price during the last 30 minutes excluding the abnormal minutes (identified by the IQR criterion) and the settlement (official closing) price on the event day.

Reversal $1 \mathrm{~min}$ (\%) The percentage return on the stock in the first minute of trading on the next day (after the event day) in excess of the Nifty return over the same period. The return is computed from the last traded price on the event day and not the settlement (official closing) price.

Reversal $30 \mathrm{~min}$ (\%) The percentage return on the stock in the first 30 minutes of trading on the next day (after the event day) in excess of the Nifty return over the same period. The return is computed from the last traded price on the event day and not the settlement (official closing) price.

\subsection{High Frequency Manipulation of Settlement Price}

In the previous table, we look for instances where the following two additional conditions are met:

1. There is a dislocation of the settlement price by at least $1 \%$ by both the measures that we have computed. Only Company 3, Company 5 and the second instance of Company 6 meet this test.

2. The open interest ratio is at least 1.5. Out of the three instances identified above, Company 5 does not meet this test.

Company 3, and the second (September 27, 2012) instance of Company 6 meet both the dislocation test and the open interest test. As described in detail earlier in this paper, the September 27, 2012 episode is already under investigation by SEBI. As compared to this episode, the extent of dislocation in Company 3 is smaller. It thus appears that the alleged manipulation of the settlement price on September 27, 2012 episode has at most one (milder) parallel.

However, this does not mean that high frequency manipulation is not taking place in Indian markets at expiry. On the contrary, the previous section described several instances of abnormal trading 
volumes concentrated in a few minutes at futures expiry settlement which are associated with sharp price spikes that are reversed early next day. This pattern is consistent with high frequency manipulation that seeks to exploit price insensitive execution algorithms as explained in 3.3 above.

\section{Conclusion}

We demonstrate that the combination of cash settlement with the use of a volume weighted average price (VWAP) to determine the settlement price on expiry day makes the Indian single stock futures market vulnerable to a form of high frequency manipulation that targets price insensitive execution algorithms. This type of manipulation is hard to prevent using mechanisms like position limits, and therefore it is necessary to establish a robust program to detect and deter manipulation.

We develop an econometric technique that uses high frequency data and which can be integrated with the automated surveillance system to identify suspected cases of high frequency manipulation very close to the event. Human judgement then needs to be applied to identify cases which prima facie justify detailed investigation and possible prosecution.

Our results suggest that high frequency manipulation of price insensitive execution algorithms may be taking place. However, successful manipulation of the settlement price is relatively rare with only one clear instance (the September 27, 2012 episode) and one (milder) parallel.

Finally, the use of the volume weighted average price (VWAP) to determine the cash settlement price of the futures contract might require reconsideration. 


\section{References}

Andersen, T. G. and Bollerslev, T. (1997a). Heterogeneous information arrivals and return volatility dynamics: Uncovering the long-run in high frequency returns. The Journal of Finance, 52(3):9751005.

Andersen, T. G. and Bollerslev, T. (1997b). Intraday periodicity and volatility persistence in financial markets. Journal of Empirical Finance, 4(2-3):115-158.

Andersen, T. G. and Bollerslev, T. (1998a). Deutsche Mark-Dollar volatility: Intraday activity patterns, macroeconomic announcements, and longer run dependencies. The Journal of Finance, $53(1): 219-265$.

Andersen, T. G. and Bollerslev, T. (1998b). Towards a unified framework for high and low frequency return volatility modeling. Statistica Neerlandica, 52(3):273-302.

Arnoldi, J. (2012). Cheating models : Algorithmic trading and the normative reconfiguration of financial trading. Paper presented at Unpacking the Crisis, Edinburgh, United Kingdom, http://pure.au.dk/portal/en/publications/cheating-models(a40d7204-79a54c7f-be60-65d7cc53bd11).html.

Cumming, D. and Johan, S. (2008). Global market surveillance. American Law and Economics Review, 10(2):454-506.

Cumming, D., Zhan, F., and Aitken, M. (2012). High frequency trading and end-of-day manipulation. Available at SSRN: http: //ssrn. com/abstract $=2145565$.

Financial Services Commission Korea (2011). Unfair Trading Investigation and Results: Violation of prohibition on market manipulation through the link between spot and futures by KOSPI200 stocks and derivatives trading on November 11, 2010, a KOSPI200 options' expiry date. http: //www.fsc.go.kr/downManager?bbsid=BBS0048\&no=73803. Accessed: July 25, 2013.

Gallant, A. R. (1981). On the bias in flexible functional forms and an essentially unbiased form: The Fourier flexible form. Journal of Econometrics, 15(2):211-245.

Hillion, P. and Suominen, M. (2004). The manipulation of closing prices. Journal of Financial Markets, 7(4):351-375.

Järvinen, S. and Käppi, J. (2004). Manipulation of the bund futures market. Applied Financial Economics, 14(11):799-808. 
Jeanneau, S. and Scott, R. (2001). Anatomy of a squeeze. BIS Quarterly Review, 2001(June):32-33.

Jeanneau, S. and Scott, R. (2002). Playing cat and mouse in market squeezes. BIS Quarterly Review, 2002(June):32-33.

Kumar, P. and Seppi, D. J. (1992). Futures manipulation with "cash settlement". The Journal of Finance, 47(4):1485-1502.

Markham, J. W. (1991). Manipulation of commodity futures prices - the unprosecutable crime. Yale Journal on Regulation, 8:281-388.

Pirrong, C. (2004). Detecting manipulation in futures markets: The ferruzzi soybean episode. American Law and Economics Review, 6(1):28-71.

Pirrong, C. (2010). Energy market manipulation: definition, diagnosis, and deterrence. Energy Law Journal, 31:1-20.

Securities and Exchange Board of India (2013a). Directions under Sections 11 and 11B of the Securities and Exchange Board of India Act, 1992 against Aventis Biofeeds Private Ltd. and other connected entities in the matter of dealing in the scrip of Ruchi Soya Industries Limited. http://www.sebi.gov.in/cms/sebi_data/attachdocs/1360931136038.pdf. Accessed: April $12,2013$.

Securities and Exchange Board of India (2013b). Order under Section 11 and 11B of the Securities and Exchange Board of India Act, 1992 with regard to Aventis Biofeeds Private Ltd. and others - in the matter of dealing in the scrip of Ruchi Soya Industries Limited. http://www.sebi.gov . in/cms/sebi_data/attachdocs/1386395529169.pdf. Accessed: December 7, 2013.

Wheatley, M. (2012). The Wheatley Review of LIBOR: Final Report. HM Treasury, United Kingdom. 


\section{Appendix: Price and Volume During Suspected Manipulation}

\section{Events}

The plots in this appendix show the minute by minute volume and price during the expiry day and the next day for each suspected manipulation event. The upper panel shows the volume (on a log scale) and the lower panel the price with the expiry day open price normalized to 100 . Within each panel, the left plot is for the expiry day and the right plot is for the next trading day. The company number is shown at the top of the chart and the dates of the event and the next trading day are at the bottom of the chart.

The expiry day price chart also shows the volume weighted average price prior to the last 30 minutes as a dotted horizontal line.

The following additional data is also displayed on each chart:

- The minute in which the peak volume occurred.

- The model based measure of abnormal volume: the number of standard deviations (sd) by which the peak log volume exceeded the predicted volume from Eq 1. This is just the standardized residual from that regression.

- The model free measure of abnormal volume: the number of inter quartile ranges (IQRs) by which the peak volume exceeded the higher of (a) the third quartile of the last 30 minutes and (b) the maximum volume prior to the lat 30 minutes

- The abnormal price movement on expiry day measured by the excess return (over the Nifty return) during the last 30 minutes.

- The price recovery on the next day measured by the excess return (over the Nifty return) during the first minute.

- The price recovery on the next day measured by the excess return (over the Nifty return) during the first 30 minutes. 


\section{Company 1}
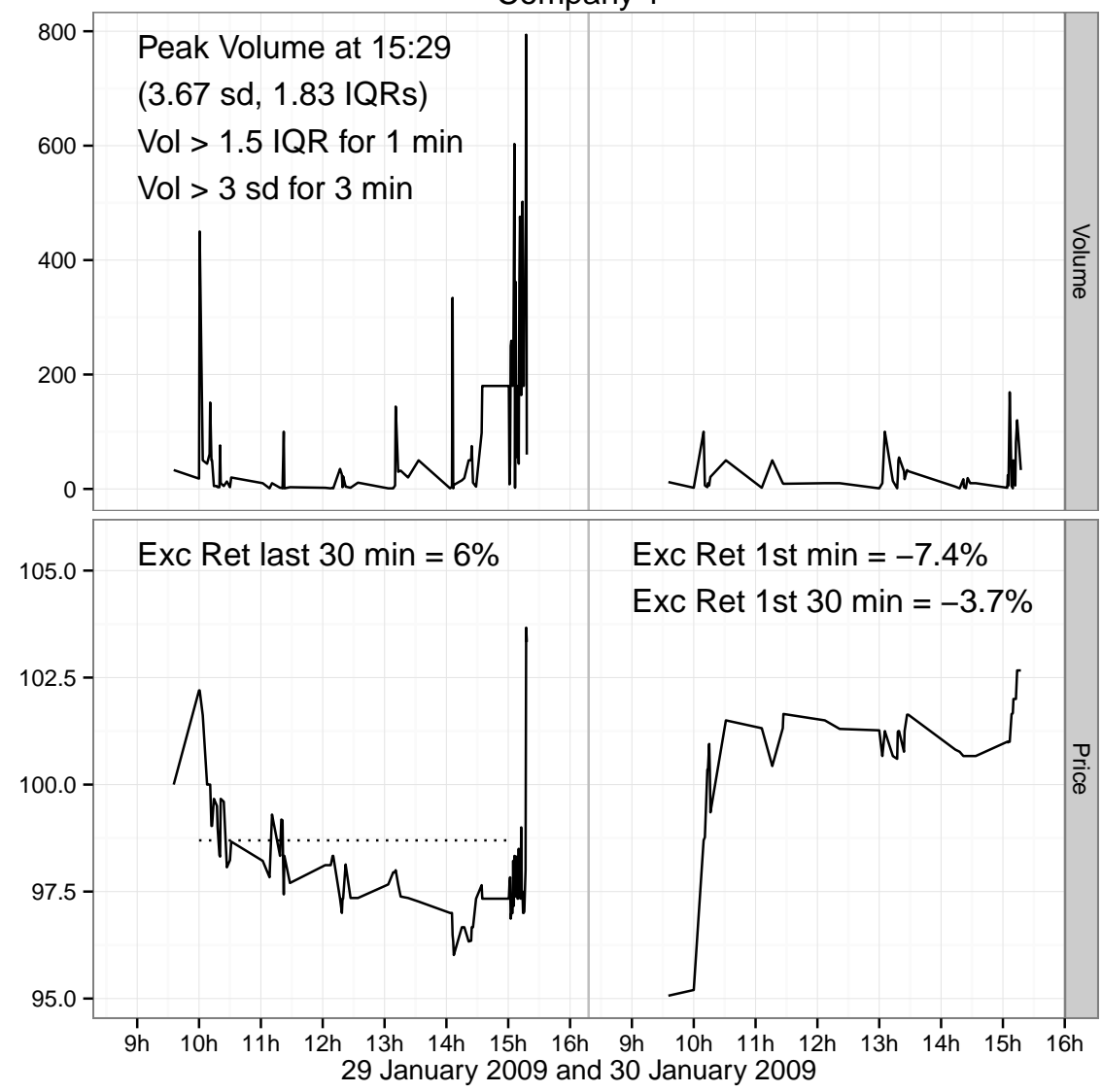

Company 2
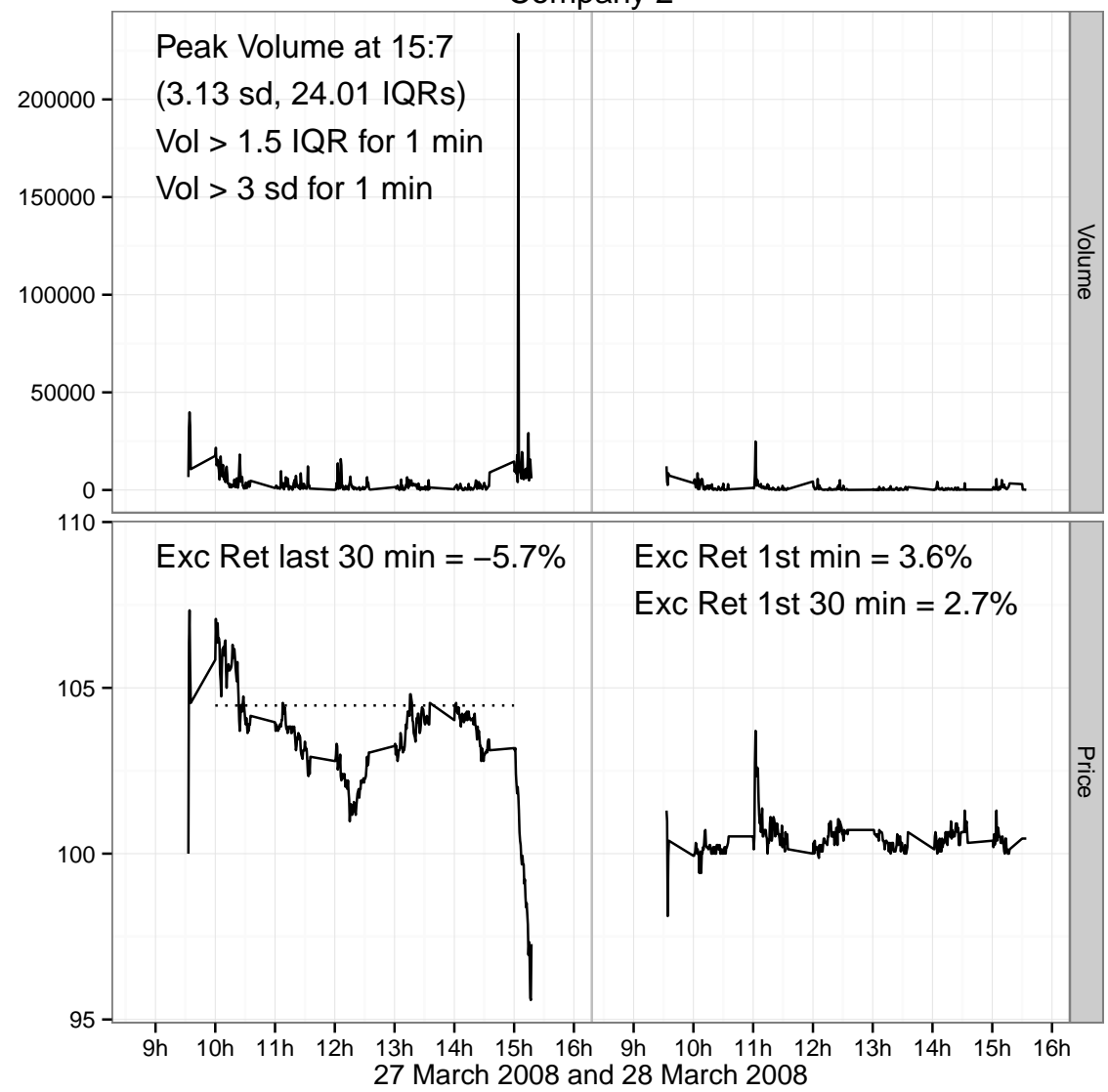


\section{Company 3}
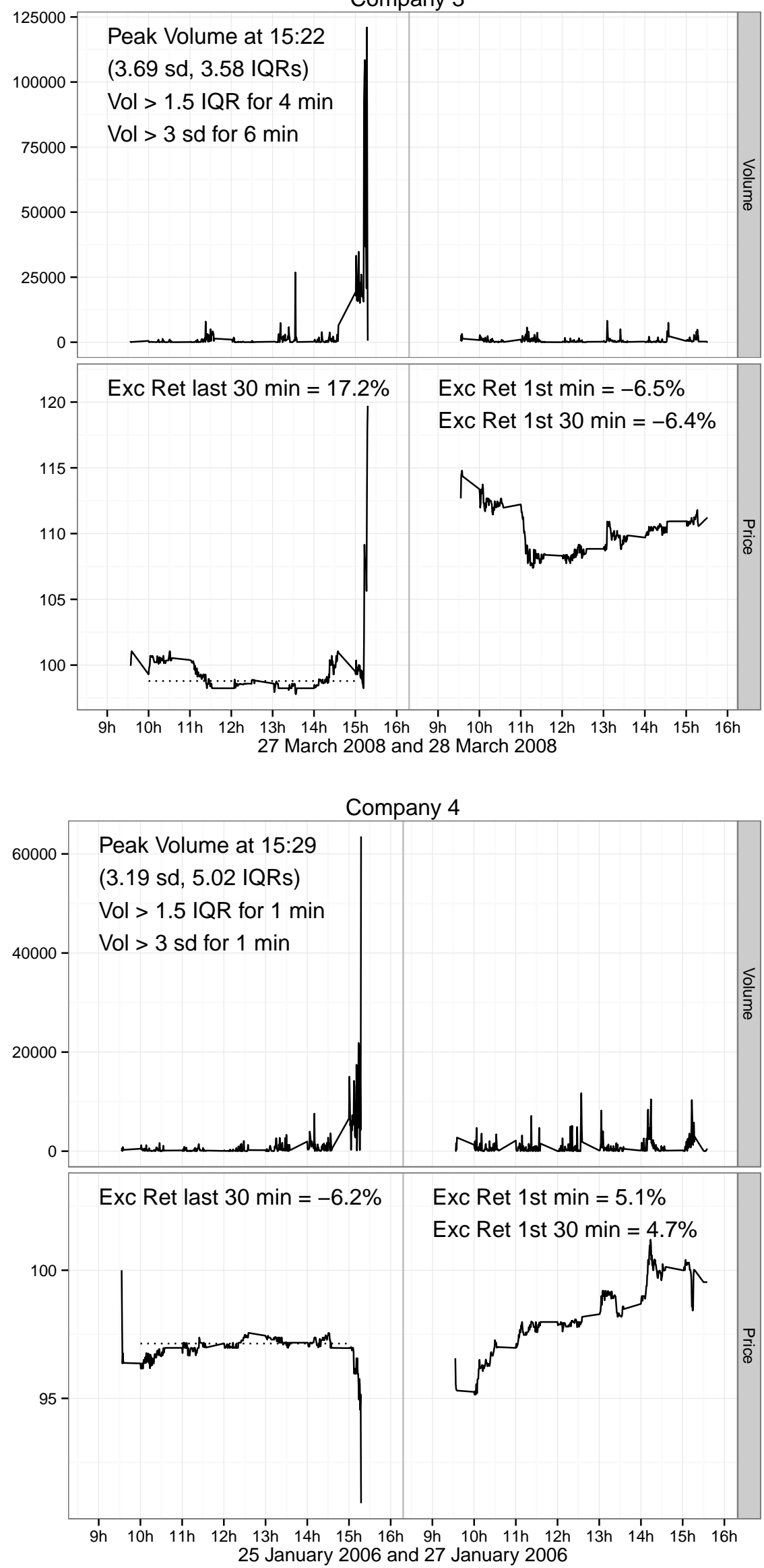
Company 5
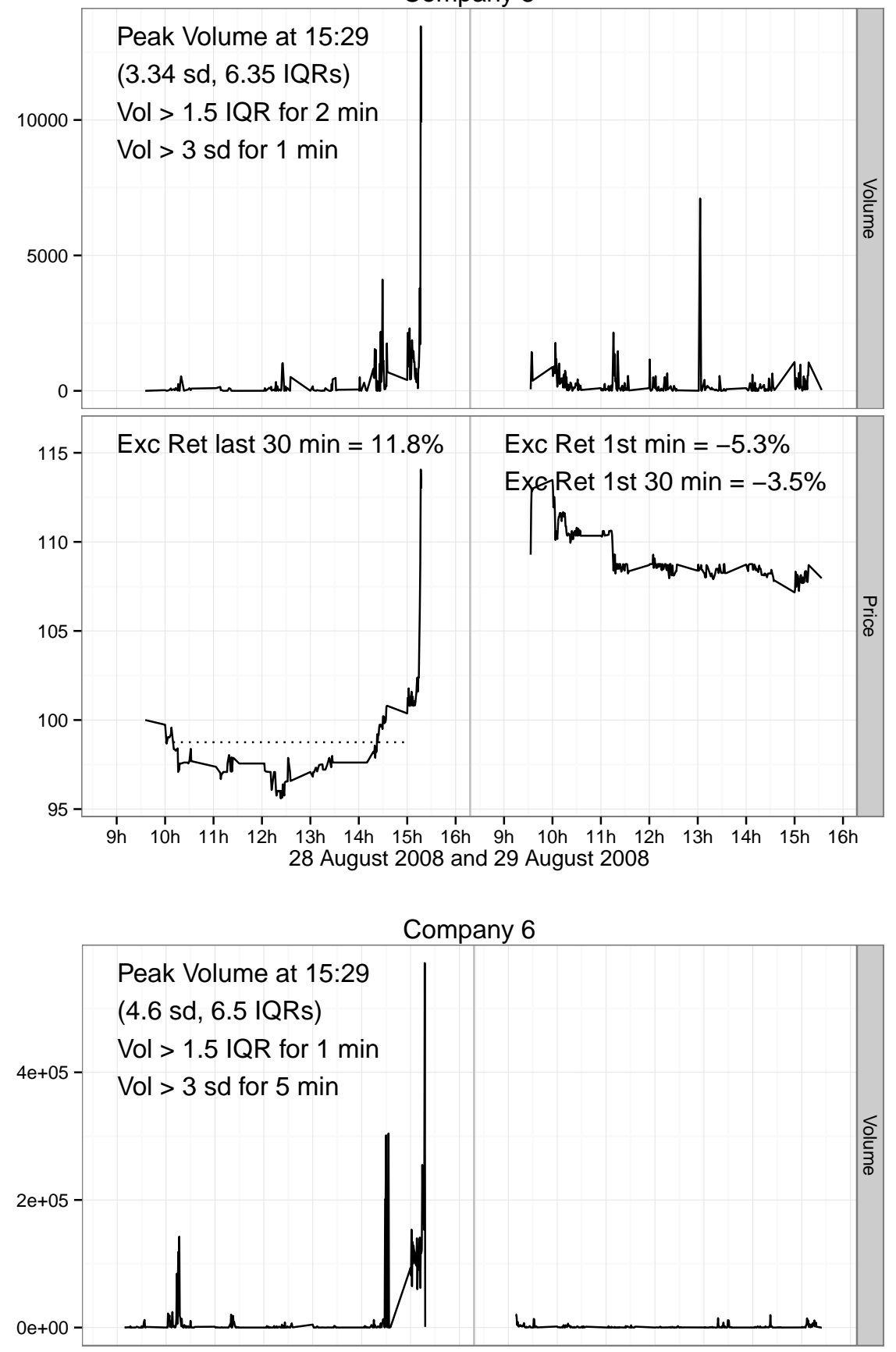

Exc Ret last $30 \mathrm{~min}=6.9 \%$

Exc Ret 1 st $\min =-3.9 \%$

Exc Ret 1 st $30 \mathrm{~min}=-5.5 \%$

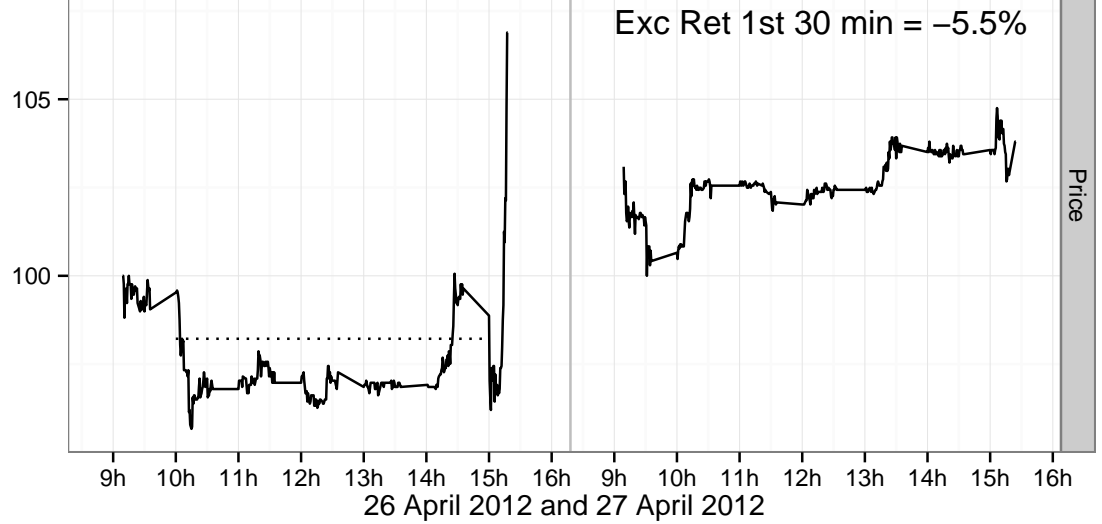


Company 6
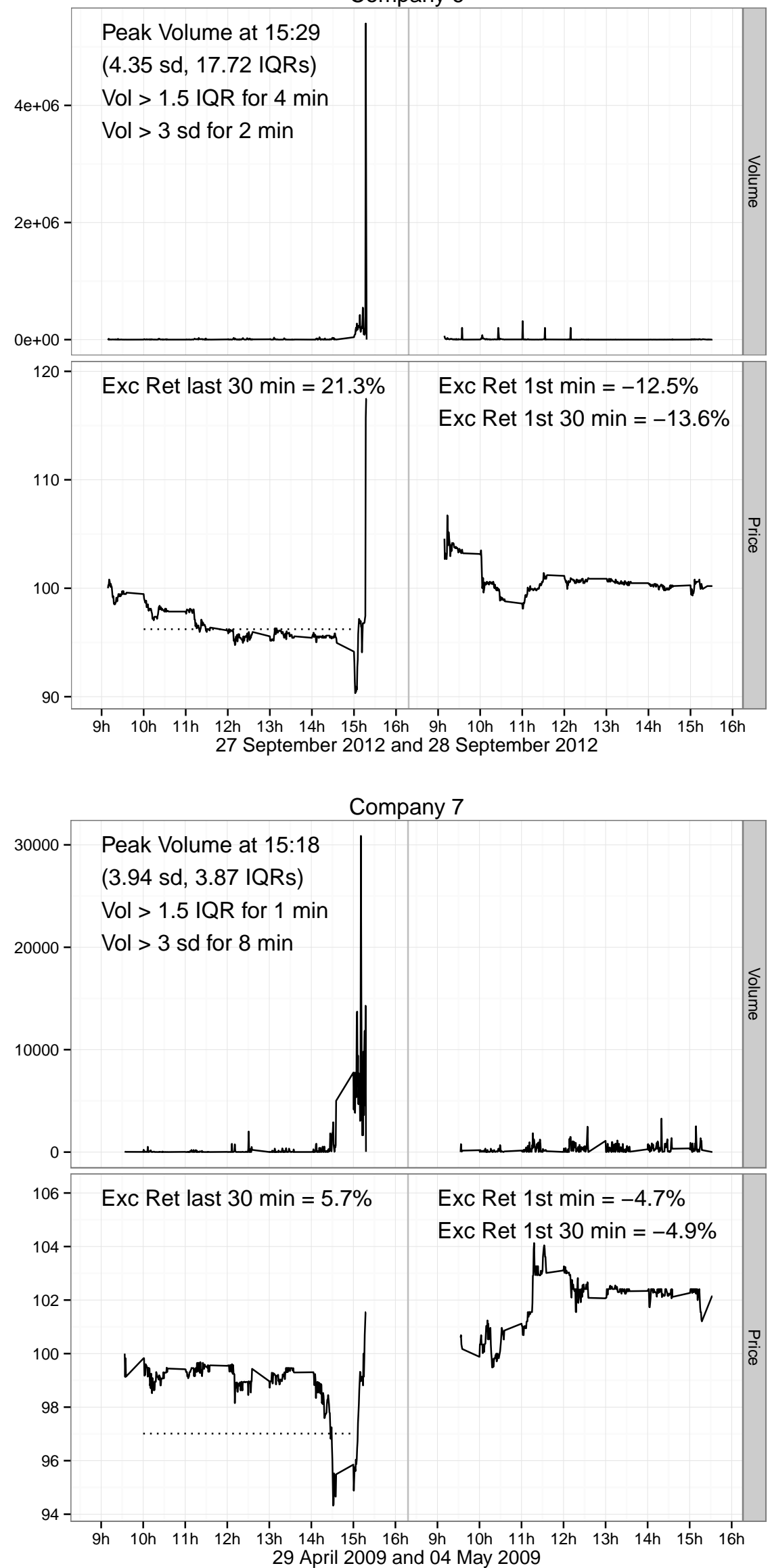